\title{
Die 'aposunagogos' se invloed op die geskrifte van die Nuwe Testament volgens Walter Schmithals
}

P B Boshoff

Tydelik-deeltydse dosent: Departement Nuwe-Testamentiese Wetenskap (Afd A)

Universiteit van Pretoria

\begin{abstract}
The influence of the 'aposunagogos' on the writings of the New Testament according to Walter Schmithals

The essay puts the view of Schmithals' of the historical circumstances behind a great part of the writings of the New Testament. He makes 'aposunagogos' the terminus technicus referring to what happened in the background. 'Aposunagogos' refers to the exclusion of Christians, confessing Jesus as the Messiah, from the synagogue in the years following the destruction of the temple in $70 \mathrm{AD}$ by the Romans. Several texts are being discussed reflecting the power of Schmithals' exegesis.
\end{abstract}

\section{INLEIDING}

Die behoefte bestaan lank reeds dat die uitleg van die Nuwe Testament verbind moet wees aan 'n rekonstruksie van die historiese situasie van die oer-Christendom. Die omstandighede waarin die geskrifte tot stand gekom het, het daaraan help skryf. Die eksegeet moet probeer agterkom wat die die skrywer uitgelok het om te skryf. Wat het daar in die omgewing geskuil? As hy daarin kan slaag om die geleentheid van die woorde te ontdek, begin die letters om te praat, want die taal is vergroei met die omstandigheid of situasie waarin dit gesê is. Van die mate waarin die uitlegger hierdie vergroeiing kan aantoon, hang die waarde van sy eksegese af.

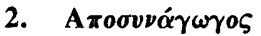

\subsection{Historiese inkleding}

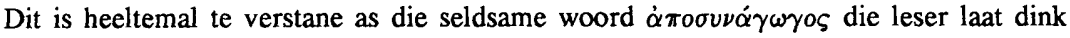
dat hy hiermee 'n onbekende terrein betree. Die woord is 'n samestelling uit die voorsetsel $\dot{\alpha} \pi o ́$ ('weg van') en $\sigma \nu \nu \alpha \gamma \omega \gamma \dot{\eta}$ ('sinagoge'). Iemand wat uit die sinagoge uitgesluit is, word as aposunagogos beskryf. Dit is 'n Johanneswoord wat in die Nuwe

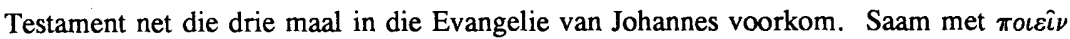


vorm 'n aposunagogos 'n aktiewe kombinasie: 'Hulle sal julle uit die sinagoge uitsluit' (Joh 16:2). Die passiewe vorm word met $\gamma \varepsilon \nu \varepsilon \dot{\varepsilon} \sigma \theta e \alpha \iota$ uitgedruk: 'Ook baie van die lede van die Joodse Raad het in Hom geglo, maar uit vrees vir die Fariseërs het hulle dit nie bely nie, om nie uit die sinagoge uitgesluit te word nie' (Joh 12:42). En die derde voorbeeld: 'want die Jode het reeds besluit gehad, dat elkeen wat Jesus as die Christus bely, uit die sinagoge uitgesluit word' (Joh 9:22).

Hoewel hierdie gegewens maar min en effens lyk, kan die oplettende student belangrike aantekeninge daaroor maak. Martyn (1968:18-22; vgl Vouga 1977:51-52; Wengst 1981:48-52) wys daarop dat 'n gesaghebbende Joodse vergadering tot ' $n$ formele besluit gekom het oor wat die regte optrede sou wees teenoor Jode wat bely dat Jesus die verwagte Messias is. Sulke belyers moet uit die sinagoge uitgesluit word. Lidmaatskap van die sinagoge kan nie meer versoen word met lidmaatskap van die gemeente nie. Johannes gee ook die inligting dat dit Jode en by name die Fariseërs is wat die dryfkrag agter die ordereël sou wees.

Schmithals (1985:358; 1987:271-374; 1993; 1994a:231) gebruik aposunagogos as terminus technicus om die uitsluiting van die Joodse Christene uit die sinagoge in die tydperk na die verwoesting van die tempel in $70 \mathrm{n} \mathrm{C}$ te beskryf. Tot en met die verwoesting van die tempel het die Joodse Christene as deel van die Jodedom beskerming as ' $n$ bevoorregte godsdiens in die Romeinse ryk geniet. Na die verlies van die tempel het die Fariseërs die Jodedom herorganiseer met as middelpunt die Farisese interpretasie van die tora. Die Joods-Christelike kerk is met dié wet as nuwe middelpunt binne die sinagoge gekonfronteer, want diegene wat nie met die nuwe benadering wou saamgaan nie, moes die sinagoge verlaat: aposunagogos. Die Joodse Christene sowel as die heiden-Christene wat voorheen as 'godvresendes' deel van die sinagoges was, kon nie langer onder die veilige dak van Jodedom bly en nog hulle belydenis handhaaf nie. Gevolglik moes hulle die sinagoge verlaat.

Die herorganisasie van die Jodedom was nie net aan die vernuf van die Fariseërs, om voordeel uit die verwarring wat daar in Palestina was met die opstand en verwoesting van die tempel, toe te skryf nie (vgl Vouga 1977:63). Volgens oorlewering het Johanan ben Zakkai in daardie onstuimige oorlogstyd reeds van keiser Vespasianus toestemming gekry om in Jabne 'n Rabbynse Akademie te open. Schmithals (1987: 372; 1989:26; 1994:231) maak die afleiding dat die Farisese ordening van die Joodse gemeenskap ook in die belang van die Romeinse staat was, omdat die Fariseërs standpunt teen die Selotiese opstand ingeneem het en 'n stabiliserende faktor in die Joodse Diaspora was. Dit het makliker geword om te bepaal wie as Romeinse burger ook nog Joodse voorregte geniet het, en wie die volle drag van sy Romeinse burgerskap moes 
dra. Jodechristene wat uit die sinagoge uitgesluit word, verloor die voordele wat aan die Jode toegestaan is en behoort voortaan aan die kultus van die keiser en die godin Roma deel te neem. Betaal hulle nie die Joodse belasting van die fiscus Judaicus nie, en neem nie aan die verpligte kultusse deel nie, wek hulle agterdog by die staat dat hulle opstandiges is.

Die sinagoge het dié wegbrekers as drosters beskou en hulle by die Romeinse owerheid aangegee, ook ter wille van die Farisëers se eie beskerming. 'n Groep wat met die sinagoge geassosieer word en nie die ooreengekome gedragsreëls volg nie, kon die oorsaak daarvan wees dat die staat op die sinagoge self toeslaan. Teen die einde van die eerste eeu is die vervloeking van die ketters, die Birkat ha-Minim, in die daaglikse gebed van die Jode opgeneem en dit verteenwoordig die hoogtepunt van hierdie maatreëls. Dit was 'n openlike demonstrasie van die verwerping van die Christene wat nie meer as 'n groep binne die Jodedom beskou moes word nie.

\subsection{Matteus}

$\mathrm{Na}$ die verwoesting van die tempel het Vespasianus bepaal dat die lopende tempelbelasting voortaan deur die Jode aan die tempel van Jupiter Capitolinus in Rome betaal moes word. Hierdie belasting het verseker dat die Judaïsme in die bevoorregte posisie van ' $n$ religio licita kon bly. Die gemeente is daarvan bewus dat hulle in 'n unieke posisie is ten opsigte van die tempelbelasting, naamlik dat hulle nie meer nodig het om hierdie Joodse verpligting na te kom nie, maar dit nogtans doen om 'n konfrontasie te vermy.

Maar ons moenie hierdie mense aanstoot gee nie. Gaan see toe en gooi hoek in, en die eerste vis wat byt, moet jy uittrek. As jy sy bek oopmaak, sal jy 'n silwermuntstuk daarin kry. Vat dit en betaal hulle die belasting vir My en vir jou.

(Matt 17:27)

Hulle sou daarvan beskuldig kon word dat hulle 'n Joodse leefwyse volg, maar nie die wetlike voorwaardes daarvoor wil nakom nie. Schmithals (1994a:235; vgl ook Schmithals 1987:375) betwyfel dit of hierdie taktiek die gemeente vir lank aan die veilige kant sou kon hou.

Schmithals (1983:27; 1985:375; 1994a:235-236) situeer die Matteusevangelie in omstandighede waarin die skeidingsproses tussen sinagoge en kerk nog aan die gang is. Die Joods-Christelike gemeente verkeer onder die druk van die sinagoge en dit is nog 
nie vir almal in die gemeente duidelik dat hulle nie die herorganisasie van die Fariseërs kan volg nie. Matteus neem sterk standpunt in teen 'hulle' sinagoge en dring by die gemeente aan om die Christelike weg enduit te loop:

Pas op vir die mense. Hulle sal julle aan die geregshowe uitlewer, en in hulle sinagoges sal hulle julle gesel. Ook voor goewerneurs en konings sal julle gebring word ter wille van My. Dit sal julle geleentheid wees om voor hulle en die heidennasies van My te getuig. Wanneer hulle julle uitlewer, moet julle julle nie bekommer oor hoe of wat julle moet sê nie, want op daardie oomblik sal God aan julle gee wat julle moet sê. Dan is dit nie julle wat praat nie, maar die Gees van julle Vader wat deur julle praat.

(Matt 10:17-20)

In hierdie verse word die vervolgingsituasie van die Joods-Christelike gemeente geteken. Die sinagoge het in die Diaspora-regsbevoegdheid om teen die rebelle op te tree, terwyl die Romeinse regsfeer ook genoem word as rimte waarin getuienis afgelê word. Matteus troos en bemoedig die gemeente deur hulle daarop te wys dat hulle niks hoef te doen nie, die Gees van God sal die nodige sê. God is in beheer ook van hierdie situasie, nie die Christene nie en ook nie hulle vervolgers en regters nie. Deur in die moeilike omstandighede vas te hou aan die belydenis word die gemeente die sout van die aarde en die lig vir die wêreld. Die respek en erkenning wat die reglose en onmagtige, 'sagmoedige' gemeente behoort af te dwing, maak dat 'julle' Vader verheerlik word wanneer die gemeente die kwaad wat hulle aangedoen word, met die goed wat hulle doen, oorwin (Schmithals 1983:34; 1985:377; 1987:376; 1994a:235).

Om die invloed van die Fariseërs in die gemeente teen te werk, moet daar leertug toegepas word. Schmithals identifiseer die broer wat teen jou sondig, met iemand wat 'n vreemde leer voordra:

As jou broer teen jou sondig, gaan wys hom tereg waar julle eenkant alleen is. As hy na jou luister, het jy jou broer teruggewen. Maar as hy nie luister nie, neem nog een of twee met jou saam, sodat alles wat gesê word, deur die woord van twee of drie getuies bevestig kan word. As hy na hulle nie luister nie, sê dit vir die gemeente. As hy ook na die gemeente nie luister nie, moet $\mathrm{jy}$ hom as 'n heiden en ' $\mathrm{n}$ tollenaar behandel. 
Hierdie tug moes toegepas word met die voortdurende plig om te vergewe en om die wat uitgesluit is, weer in die gemeente op te neem (Schmithals 1985:378; 1987:376; 1994a:235-236).

Vir Matteus is dit ook belangrik dat die gemeentelede hulle moes laat doop. Hierdie stap het verseker dat die dopeling hom definitief van die sinagoge afskei en met die gemeente verbind. In hierdie opsig dien Jesus se aandrang om gedoop te word vir almal tot voorbeeld. So word aan die 'geregtigheid' voldoen (Schmithals 1978:77; 1985:377; 1987:376; 1994a:236):

Maar Johannes het dit probeer verhinder deur te sê: 'Ek moet eintlik deur U gedoop word, en U kom na my toe?' Jesus het hom geantwoord: 'Nogtans moet jy dit nou doen, want so pas dit ons om alle geregtigheid te vervul.

(Matt 3:14-15)

Op die beskuldiging van die sinagoge dat die Christelike geloof die wet en die profetiese verkondiging ophef, antwoord Matteus dat dit nie gebeur nie, die wet en die profete word eerder deur Jesus, die Messias vervul. Teenoor die Jodedom maak die kerk daarop aanspraak dat hulle wet die ware wet is (Schmithals 1985:378; 1987:376; 1994a:236):

Ek sê vir julle: 'As julle getrouheid aan die wet nie meer inhou as die van die Skrifgeleerdes en Fariseërs nie, sal julle nooit in die koninkryk van die hemel ingaan nie'.

(Matt 5:20)

In aansluiting by die gedagte van die vervulling van die wet en gemik daarop om die skeiding tussen kerk en sinagoge te bewerkstellig, voer Matteus sy twaalf vervullingsitate aan, om daardeur aan te toon dat Jesus die verwagte Messias is, byvoorbeeld: 'Dit het alles gebeur sodat die woord wat die Here deur sy profeet gesê het, vervul sou word' (Matt 1:22). 


\subsection{Lukas}

Anders as Matteus wat midde in die aposunagogos skryf, het Lukas die skeiding tussen sinagoge en kerk reeds agter die rug. Lukas kyk terug op die vervolging van Christene wat enersyds tot martelaarskap en andersyds tot afvalligheid gelei het (Schmithals 1985:359; 1987:377; 1994a:236-238):

Aan julle my vriende, sê Ek: 'Moenie bang wees vir die wat die liggaam doodmaak en daarna niks verder kan doen nie. Ek sal vir julle sê vir wie julle bang moet wees: Vir Hom wat mag het om, na die dood, in die hel te werp. Ja, Ek sê vir julle, Hom moet julle vrees'.

(Luk 12:4-5

Met die oog op moontlike martelaarskap gee Lukas die raad aan die gemeente om nie te protesteer nie en om blymoedig te bly. 'n Mens behoort jou soos Paulus en Silas te gedra as jy ter wille van jou geloof in die tronk beland (Hand 16:23-25; Schmithals 1982:151).

Aan die adres van die Romeinse owerheid rig Lukas die boodskap dat die beskuldiging teen die kerk dat hy polities onbetroubaar is, van alle waarheid ontbloot is. Paulus, die groot heidensendeling, was dan 'n Romeinse burger en die owerheid het vroëer die Christene se onskuld toegegee (Schmithals 1982:153-154):

Die bewaarder het toe die boodskap aan Paulus oorgedra en gesê: 'Die stadsbestuur het laat weet dat julle losgelaat moet word. Julle kan nou gaan, en voorspoed op julle reis!' Maar Paulus sê vir die polisie: 'Ons is sonder verhoor in die openbaar geslaan en in die tronk gestop, ons wat Romeinse burgers is. En nou wil hulle ons stilletjies hier wegkry. O nee! Laat hulle self kom en ons uitlei.' Die polisie het toe vir die stadsbestuur gaan vertel. Die het groot geskrik toe hulle hoor dit is Romeinse burgers. Hulle het gegaan en om verskoning gevra, hulle uit die tronk uitgelei en hulle versoek om die stad te verlaat.

(Hand 16:36-39)

Lukas wys op die welwillende houding van owerheidspersone teenoor die gemeente. As voorbeeld kan Gallio geneem word: 
Nadat Gallio goewerneur van Agaje geword het, het die Jode egter soos een man teen Paulus in opstand gekom en hom voor die hof gebring. 'Hierdie man,' het hulle gesê, 'probeer die mense oorhaal om God op 'n manier te vereer wat in stryd is met ons wet.' Paulus wou praat, maar toe sê Gallio vir die Jode: 'As dit oor 'n onreg of 'n ernstige misdaad gegaan het, was dit my plig om geduldig na julle Jode te luister. Maar aangesien dit ' $n$ geredekawel is oor woorde en name en julle eie wet, moet julle self daaroor beslis. In sulke sake wil ek nie regter wees nie.'

(Hand 18:12-15)

Hiermee wil Lukas op 'n aanskoulike wyse tuisbring wat die staat se houding teenoor die kerk behoort te wees: Die staat behoort hom nie in geloofsvrae in te meng nie (Schmithals 1982:167).

Die hoë waardering wat Lukas vir die vrou het, situeer Schmithals ook in die vervolgingsomstandighede. Hulle was minder as die mans blootgestel en deur versorging in die dae van nood en vervolging te verskaf het hulle na vore getree as ware steunpilare. Die gemeentelede wat hulle besittings verloor het ter wille van die belydenis was afhanklik van die hulp wat uit die gemeente kon kom. Lukas verwys byvoorbeeld hierna waar hy vertel dat ' $n$ ' aansienlike getal vooraanstaande vroue ook bygekom het' (Hand 17:4; Schmithals 1982:156; vgl ook Schmithals 1975:164-165). Lukas is nie net evangelis van die vroue en van die armes nie, maar ook in dieselfde raamwerk die evangelis van die gebed. Byvoorbeeld as Petrus in die tronk is, bid die gemeente aanhoudend vir hom tot die Here (vgl Hand 12:5). In hulle omstandighede kan hulle niks anders vir hulle gevangenes doen as om vir hulle te bid nie (Schmithals 1982:117; 1994b:367).

\subsection{Die Johannesevangelie}

Schmithals maak gebruik van die goeie insigte van Martyn, Wengst en Vouga om sy eie konstruksie te maak in verband met die verhouding van die Johannesevangelie tot die aposunagogos. Hy bevind dat die grondevangelie, ongeveer die helfte van die Johannesevangelie, in die laaste dekade van die eerste eeu, in die raamwerk van die aposunagogos geskryf is (Schmithals 1992:158-159, 421; 1994a:239). Die grondevangelis skryf sy evangelie om die gemeente opnuut aan hulle belydenis te herinner en hulle daarin te bevestig. Tegelykertyd wil hy diegene onder die Jode wat met die kerk simpatiseer, soos Nikodemus, maar wat in die vervolgingsituaise dit nie openlik wil waag om uit die sinagoge te tree en hulle deur die doop by die Christelike gemeente te voeg nie, aanmoedig om die stap te neem (Schmithals 1992:312, 315, 330, 331). Enige werklike leraar van Israel behoort hom te laat doop (Joh 3:10). 
Johannes die Doper getuig teenoor die offisiële afvaardiging van die Jode dat hy nie self die Christus is nie, maar van Jesus sê hy:

Ek het self ook nie geweet wie Hy is nie, maar God wat my gestuur het om met water te doop, het vir my gesê: 'Die Een op wie jy die Gees sien kom en bly, dit is Hy wat met die Heilige Gees doop.' Ek het dit gesien en daarom getuig ek: Hy is die Seun van God.

(Joh 1:33-34; Schmithals 1992:321)

By die bruilof in Kana toon Jesus in die Joodse land sy Messiaanse heerlikheid deur 'n wonder: 'En sy dissipels het tot geloof in Hom gekom (Joh 2:11; Schmithals 1992: 327). Die grondevangelis verander aan die sinoptiese teks oor die genesing van die offisier se slaaf (Luk 7:1-10) en maak van die heidense offisier 'n regeringsbeampte of Herodiaan, 'n Jood dus. Hierdie Jood raak oortuig dat Jesus die Messias is (Joh 4:46b47; 50-54a; Schmithals 1992:341). Jesus se redevoering met die Samaritaanse vrou ontwikkel so dat Hy self betuig dat Hy die Messias is: 'Dit is Ek, Ek wat met jou' praat' (Joh 4:26). Vir die Jode sê Jesus: 'Julle sal in julle sonde sterwe. Waar ek heen gaan, kan julle nie kom nie' (Joh 8:21). In sy afskeidsrede verseker Jesus egter diegene wat in Hom glo, dat Hy heen gaan om vir hulle plek te maak en dat Hy weer sal kom om hulle saam te neem (Joh 14:3). Daarby word nog 'n 'Ek is'-formule gevoeg om veral die sinagoge as ' $n$ buite-Christelike moontlikheid tot heil uit te sluit: ' $E k$ is die weg en die waarheid en die lewe. Niemand kom na die Vader toe behalwe deur My nie' (Joh 14:6; Schmithals 1992:389-390). Dit word gesê met die veronderstelling dat die heil uit die Jode kom (Joh 4:22).

\subsection{Ander Nuwe-Testamentiese geskrifte}

Schmithals (1987:373-374; vgl 1994a:240-241) gaan so ver as om te beweer dat die omstandighede van die aposunagogos 'n aansienlike rol gespeel het om die karakter van die geskrifte van die Nuwe Testament uit die tydperk na die verwoesting van die tempel te bepaal. Hierdie geskrifte beslaan die hele Nuwe Testament, behalwe die egte Paulusbriewe. Behalwe die tendense wat reeds behandel is, het die kerk verder te doen gehad met lidmate wat onder druk van die vervolging na die heidendom wou terugkeer. Sommige het weer die gesag van die owerheid verwerp, terwyl ander die Christendom van sy. Ou-Testamentiese bodem wou losmaak. Die vervolging van die Joodse Christene het hulle nader gebring aan die Pauliniese gemeentes, wat ook 'n onsekere bestaan gevoer het, byvoorbeeld onder die vervolging in Nero se tyd. Met alle Christene buite 
die sinagoge, het die orspronklike werksooreenkoms tussen die heidenchristene en Joodse Christene nie meer sin gehad nie, sodat die twee groepe saam die vroegkatolieke kerk kon vorm.

Schmithals (1984:18) dateer die versameling en uitgawe van die hoofbriewe van Paulus, die aan die Korintiërs, Galasiërs, Filippense, Tessalonisense en Romeine, in die tyd van die aposunagogos. Die doel van die versameling was om aan die onderskeie groeperinge binne die kerk, wat nou hulleself van nuuts af buite die sinagoge moes konstitueer, die Pauliniese erfenis tot beskikking te stel. Met die redigering en uitgawe van die hoofversameling het die bekende gedeelte van Romeine 13:1-7 sy weg in die Pauliniese korpus in gevind om as politieke apologie te dien (Schmithals 1984:162-163; 1994a:242).

Die druk wat van die sinagoge se kant af gekom het, het gewoonlik die gemeentes tot beskeidenheid gedwing waarin hulle nie veel meer kon doen as om die ander wang te draai nie. Maar dit kon ook die aanleiding wees tot anti-Joodse uitbarstings soos 'n byvoegsel by die uitgawe van Paulus se briewe met die bedoeling om rekenskap te gee van die lyding van Christene as gevolg van die optrede van die sinagoge: 'Hulle het die Here Jesus doodgemaak en die profete en het ons uitgedryf, hulle geval God nie en is vyandig teenoor alle mense' (1 Tess 2:15; Schmithals 1984:160-161; 1993:4; 1994a: 242).

Behalwe die hoofversameling onderskei Schmithals (1984:165-188) ook 'n neweversameling Pauliniese briewe, naamlik Kolossense, Filemon en Efesiërs. Byna die helfte van Kolossense en die hele brief aan die Efesiërs herlei Schmithals terug na die hand van die redakteur. Schmithals noem as die hooftema van die Efesiërbrief die vereniging van Joodse en heidense Christene in dieselfde gemeente. By die Pauliniese gemeentes word daarop aangedring om hulle geloofsbroers wat uit die sinagoge verdryf is in hulle geledere op te neem (Schmithals 1994a:241). Die brief van Jakobus spreek weer die aanvanklike bedenkinge uit teen 'n vereniging van die Joodse Christene met die Pauliniese gemeentes. Die skrywer is nie gediend met die werwing vanuit die Pauliniese gemeentes onder die aposunagogos Christene nie. Hy vrees dat die Paulus mense 'n geloof sonder werke voorstaan (Schmithals 1989:27-28).

\section{SLOTOPMERKING}

Die leser kan nie anders nie as om onder die indruk te kom dat Schmithals 'n indrukwekkende voorbeeld van historiese uitleg aanbied. Hierdie soort uitleg kan nie van die beswaar dat dit in 'n sirkel beweeg ontsnap nie: Die omstandighede help om die teologiese taal te verstaan as 'n reaksie daarop, maar die eksegeet lei eers uit die reaksie af wat die omstandighede sou kon wees. Die beswaar van 'n sirkelredenasie tref egter die 
historiese metode as sodanig en nie net die poging van Schmithals nie. Alle historiese eksegese beweeg in so 'n sirkel. Werklike kritiek op Schmithals se resultate sou uit 'n beter sirkel van uitleg of historiese verklaring van die tekste moet bestaan.

\section{Literatuurverwysings}

Martyn, J L 1968. History and theology in the Fourth Gospel. New York: Harper \& Row.

Schmithals, W 1975. Lukas - Evangelist der Armen. ThViat XII,153-167. 1978. Meditation zu Mt 3, 13-17. GPM 33, 75-81.

- 1983. 'Selig sind die Friedfertigen' - Was meint die Bergpredigt wirklich? in Bekenntnis und Gewissen: Theologische Studien zur Ethik. Zum 60. Geburtstag herausgegeben von Hess, H-E \& Wildemann B. Berlin: CZV-Verlag.

1984. Die Briefe des Paulus in ihrer ursprüngliche Form. Zürich: Theologische Verlag. (Zürcher Werkkommentare zur Bibel.)

- 1985. Einleitung in die drei ersten Evangelien. Berlin: De Gruyter. (De Gruyter Lehrbuch.)

- 1987. Der Konflikt zwischen Kirche und Synagoge in neutestamentlicher Zeit, in Oeming, M \& Graupner, A (Hrsg), Altes Testament und christliche Verkündigung: Festschrift für Antonius H J Gunneweg zum 65. Geburtstag, 366-386. Stuttgart: Kohlhammer.

1989. Paulus und Jakobus - ein theologischer Gegensatz? Christliches $A B C$ heute und morgen 4, 19-29.

1992. Johannesevangelium und Johannesbriefe: Forschungsgeschichte und Analyse. Berlin: De Gruyter. (BZNW 64.)

- 1993. Das Verhältnis von Juden und Christen in neutestamentlicher Zeit. Treffpunkt Matthäus, Evangelisches Gemeindeblatt der Matthäusgemeinde Steglitz, 3-4.

1994a. Theologiegeschichte des Urchristentums: Eine problemgeschichtliche Darstellung. Stuttgart: Kohlhammer.

- 1994b. '16. Zonntag nach Trinitatis. Apg. 12, 1-11, in GPM 48, 364-369.

Vouga, F 1977. Le cadre historique et l'intention theoliogique de Jean. Paris: Beauchesne. (Beauchesne Religions 3.)

Wengst, K 1981. Bedrängte Gemeinde und verherrlichter Christus: Der historische Ort des Johannesevangeliums als Schlüssel zu seiner Interpretation. NeukirchenVluyn: Neukirchener Verlag. (Biblisch-Theologische Studien 5.) 